\title{
Time series effects of dissolved oxygen and nitrogen on Long Island Sound lobster harvest
}

\author{
Zinnia Mukherjee ${ }^{1}$, Dipak K. Dey ${ }^{2}$ and Rangan Gupta ${ }^{3}$
}

\begin{abstract}
:
The formation of hypoxic water zones in marine ecosystems across the world is a growing concern among marine scientists and regulatory agencies that focus on marine resource management. In the United States, a number of water systems such as the Gulf of Mexico, Long Island Sound, and the Chesapeake Bay experience hypoxic conditions annually. Nutrient rich water with excessive nitrogen content is widely recognized as a key anthropogenic cause that lead to development of hypoxic zones. While the dissolved oxygen level indicates the presence of hypoxic water conditions, at any given time, the aquatic nitrogen concentration indicates the possibility of formation of hypoxic zones in future time periods. Hence, understanding the effects of both these variables on current and future fish population is important for improved water quality management and sustainability of marine resources. In this paper, we estimate the temporal effects of these two key variables on lobster harvest from three contiguous fishing zones in the Long Island Sound that vary in ambient water quality. We find there is no contemporaneous effect of these variables on harvest in both the zone that experience hypoxia and the two zone that do not. While there is some evidence of lagged effects of these variables on harvest, no systematic pattern emerges in these effects that distinguishes the hypoxic fishing zone with non-hypoxic zones.
\end{abstract}

Keywords: hypoxia, temporal effects, dissolved oxygen, nitrogen, lobster, harvest

\section{Introduction}

The current status of global marine resources has serious implications for sustainability of commercial fisheries. With widespread water pollution problems, rising water temperature, and over exploitation of fisheries, water quality and marine resource management has become more challenging than ever before. Given that oceans and marine waterways are a primary source for food supply to a rising global population, assessing the impact of changes in water quality on fish stock remains a critical challenge for countries. Scientific measures exist and are used by scientists and renewable resource managers, particularly in the developed world, to assess changes in water quality levels. However, isolating the effect of any ecological stress on different types of fish stocks has proven highly complicated for a variety

\footnotetext{
${ }^{1}$ Corresponding author. Department of Economics, Simmons College, 300 The Fenway, E-203J, Boston, MA 02115, USA. Email: zinnia.mukherjee@simmons.edu.

${ }^{2}$ Department of Statistics, College of Liberal Arts and Sciences, University of Connecticut, Storrs, CT 06269-3120, USA. Email: dipak.dey@uconn.edu.

${ }^{3}$ Department of Economics, University of Pretoria, Pretoria 0002, South Africa. Email: rangan.gupta@upac.za.
} 
of reasons. For example, low oxygen concentrations has been affecting a wide range of aquatic systems around the world spanning from large water zones in the middle of oceans to small lakes (Breitburg, 2002). Hypoxia or low oxygen concentrations can develop in different parts of water systems because of a number of interrelated factors such as complex hydrological features, shapes and dimensions of water basins, nutrient supplies, and food web dynamics (Breitburg et al., 2009). Given that there is considerable variation among fish species based on physiological, behavioral, and spatial characteristics, the effect of low concentrations of oxygen can vary significantly among species. For example, fast moving species may respond differently to low oxygen water zones than slow moving species. Different species exhibit different adaptive capabilities while responding to adverse environments.

Hypoxia often occurs naturally in many marine environments around the world and is a seasonal phenomenon. The primary anthropogenic cause that leads to hypoxic zone formation in water bodies is the disposal of waste materials that contain a high level of nutrients. Nitrogen helps in protein synthesis in organisms. Along with phosphorous, it is a key element that supports aquatic plant growth. However, excess nitrogen discharge in water, particularly from fertilizer use and fossil fuel emission, often lead to rapid growth of phytoplankton such as algae. The proliferation of certain types of algae leads to depletion of the oxygen dissolved in water thereby creating a shortage of oxygen supply for other organisms that share the habitat. Also, during certain times of the year, difference in water temperature and density in surface and bottom level water leads to stratification in the water column, which prevents oxygen from steadily flowing from the surface to the bottom. Low concentrations of dissolved oxygen can have both direct and indirect effects on the marine population. A direct effect of hypoxia on marine organisms is that hypoxic water zones limit the quality and quantity of habitat available to these organisms. An indirect effect of hypoxia on any species can manifest itself through the food chain by limiting availability of food sources. 
Given the interdisciplinary nature of the phenomenon, marine hypoxia has generated a widespread interest among scientists in different disciplines (for example, see Eby and Crowder (2002); Breitburg (2002); Borsuk et al., (2004); Taylor and Eggleston (2004)). Scientific studies have found evidence that hypoxia can affect different fish species in various ways such growth and mortality (for example, Peterson et al., 2000; Miller et al., 2002; Stierhoff et al., 2009; Thomas et al., 2007). While the biological effects of hypoxia on marine species are relatively well studied, the body of work that focuses on the economic consequences of hypoxia is still quite limited.

The economics literature on hypoxia has developed along two strands. One line of literature focuses on the policy issues related to the management of nutrient discharges. For example, see Ribaudo, 2005, Wu and Tanakya (2005) and Smith and Crowder (2005). Another thread of literature that has been developing over the past twenty years has attempted to analyze the effect of hypoxic water zones on fish landings. The effects of dissolved oxygen levels on fish stock have direct implication for commercial fisheries that depend on these resources for their viability. These concerns gave rise to a literature that focuses on the various impacts of hypoxia on different commercial fisheries. Focusing on the Gulf of Mexico shrimp fishery, early works by Zimmermann (1996) and Diaz (1999) showed little causal effect of hypoxic water conditions on brown shrimp harvest. More recently, Huang and Smith (2011) found that hypoxic water conditions altered the qualitative pattern of optimal harvest for brown shrimp in the Gulf of Mexico and failure to adapt to hypoxic conditions generated losses for shrimpers. In Huang et al., (2012), the authors provided evidence that showed hypoxic water conditions led to a $12.87 \%$ reduction in brown shrimp harvest in the Neuse River between 1999 and 2005. Studies based in the U.S. have mostly focused on nutrient discharges in the Mississippi watershed or the coastal hypoxia issue in the Gulf of Mexico region. 
Finding concrete evidence that illustrate the nature of effects of hypoxia on fish harvest has been challenging for a number of reasons. One key issue has been the temporal impact of the environmental variables of interest on harvest. The standard measure of hypoxia has been the dissolved oxygen level in water. Typically, hypoxic water conditions set in when the dissolved oxygen level falls below $4 \mathrm{mg} / \mathrm{l}$ and severe hypoxic conditions exist when the dissolved oxygen level is below $2 \mathrm{mg} / \mathrm{l}$. However, at any time point, the amount of nitrogen in water can affect the proliferation of algae, which can affect the level of oxygen through eutrophication. Nitrogen concentration can also affect the current growth rate of other marine species in the same environment. It can also indirectly affect the fish population of the future by affecting the dissolved oxygen concentration through eutrophication. Hence, both the oxygen and nitrogen levels can affect fish stock and harvest. These two effects depend on a number of related factors and will vary among species.

One issue of interest regarding these effects of nitrogen and oxygen is whether there is a potential time difference between these two effects. This is a very challenging question to address particularly in the context of open sea environment where a number of factors are in play. However, the issue highlights the importance of focusing on both oxygen and nitrogen to understand the net effect of hypoxic water conditions on fish stock. As far as fisheries are concerned, it underscores the relevance of studying both the contemporaneous and lagged effects of both these environmental variables on fish landings. On this premise, we analyze the long term temporal effects of two key environmental variables - dissolved oxygen and nitrogen - on lobster harvest from three fishing zones in Long Island Sound where the Connecticut lobster industry operates.

In contrast to previous economic studies that have investigated the effect of hypoxia on fish landings from the Gulf of Mexico, we chose Long Island Sound as an area of study for a couple of reasons. First, the ecosystem is of immense value to the quality of life and economy of northeastern 
United States. Second, the sound has been experiencing phases of low concentrations of oxygen every year since the eighties. In particular, every year hypoxic water zones develop in the western of the sound during the summer months, which often overlap with prime fishing season. The central and particularly the eastern zones remain unaffected. The sound supports a number of Connecticut and New York based fishing industries. The sound's water quality is a key determinant of the fish stock and the catch per unit of fishing effort for the fishing industries that operate there. We focus on lobster as it is one of the most commercially valuable species harvested in the sound and it is known to be sensitive to hypoxic water conditions.

We contribute to the literature by analyzing the lagged effects of key environmental variables that influence hypoxic water conditions - dissolved oxygen and nitrogen - on harvest from different fishing zones, only one of which experiences hypoxic conditions. We compare the lagged effects of environmental variables on harvest across zones to identify if there is any distinguishable difference in those effects in the hypoxic (west) and non-hypoxic (central and east) fishing zones. Our primary results indicate that there exist lagged effects of hypoxia related environmental variables on lobster, which provides some evidence that estimating the effect of contemporaneous dissolved oxygen on harvest may not shed light on the complete effect of hypoxia on harvest. In fact, further investigation of the relationship between nitrogen and oxygen in water at different two time periods might provide some insight on better our understanding of the effects of hypoxia on fish harvest and fish stock.

The paper is organized as follows. In the following section, we describe the data we use for the analysis. Section 3 presents the empirical model. In section 4, we discuss the results and their implications. Finally, we provide some concluding remarks in section 5. 


\section{Data}

Our dataset contains monthly observations from 1995 - 2011 for each of the three fishing zones - western LIS, central LIS and eastern LIS. The data on lobster harvest, price, and environmental variables for this study were provided by Connecticut Department of Energy and Environmental Protection. The monthly average price data for No. 2 diesel fuel for the U.S. east coast, series WPU057303, are from the Energy Information Administration. The environmental data have been collected at various stations in the sound where monitoring stations are located.

\section{Empirical Model}

Following economic theory, a fishing firm's supply can be expressed as a function of price of harvest, prices of inputs, environmental factors that affect water quality and any unobserved factor that can be a source of randomness in the harvest level. Thus, we can represent a general harvest supply function for each fishing zone as

$$
h_{t}=f\left(p_{t}, d_{t}, X_{t}, \varepsilon_{t}\right) \text {, }
$$

where harvest $\left(h_{t}\right)$ in time $t$ is a function of the price of the species $\left(p_{t}\right)$, input price $\left(d_{t}\right)$, vector of observable environmental variables $\left(X_{t}\right)$ and the unobserved factors $\left(\varepsilon_{t}\right)$. Given the above specification, we present our complete econometric model with all the lags as the following set of equations:

\section{West Zone:}

$\log h w_{t}=\alpha_{0 w}+\alpha_{h w_{-} t-i} \sum_{i=1}^{12} \log h w_{t-i}+\alpha_{p w_{-} t-i} \sum_{i=1}^{6} \log p w_{t-i}+\alpha_{d o b w_{-} t-i} \sum_{i=0}^{12} d o b w_{t-i}+$ $\alpha_{n b w_{-} t-i} \sum_{i=0}^{12} n b w_{t-i}+\alpha_{\text {tempbw }_{-} t-i} \sum_{i=0}^{6}$ tempbw $_{t-i}+\alpha_{\text {salbw }_{-} t-i} \sum_{i=0}^{6}{\text { salinityb } w_{t-i}}+\alpha_{d w} \cdot \log$ diesel $t_{t}$ $+\alpha_{\text {hyp }}$ hypoxia _ dummy $+\alpha_{\text {dieoff }}$ dieoff _ dummy $+\varepsilon_{\text {wt }}$ 


\section{Central Zone:}

$\log h c_{t}=\alpha_{0 c}+\alpha_{h c_{-} t-i} \sum_{i=1}^{12} \log h c_{t-i}+\alpha_{p c_{-} t-i} \sum_{i=1}^{6} \log p c_{t-i}+\alpha_{d o b c_{-} t-i} \sum_{i=0}^{12} d o b c_{t-i}+$ $\alpha_{n b c_{-} t-i} \sum_{i=0}^{12} n b c_{t-i}+\alpha_{t e m p b c_{-} t-i} \sum_{i=0}^{6} \operatorname{tempbc}_{t-i}+\alpha_{\text {salb }_{-} t-i} \sum_{i=0}^{6}$ salinitybc $_{t-i}+\alpha_{d c} \cdot \log$ diesel $_{t}$ $+\varepsilon_{c t}$

\section{East Zone:}

$\log h e_{t}=\alpha_{0 e}+\alpha_{h e_{-} t-i} \sum_{i=1}^{12} \log h e_{t-i}+\alpha_{p e_{-} t-i} \sum_{i=1}^{6} \log p e_{t-i}+\alpha_{d o b e_{-} t-i} \sum_{i=0}^{12} d o b e_{t-i}+$
$\alpha_{n b e_{-} t-i} \sum_{i=0}^{12} n b e_{t-i}+\alpha_{\text {tempbe }_{-} t-i} \sum_{i=0}^{6}$ tempbe $e_{t-i}+\alpha_{\text {salbe }_{-} t-i} \sum_{i=0}^{6}$ salinitybe $_{t-i}+\alpha_{d c} \cdot \log$ diesel $_{t}+\varepsilon_{\text {et }}$

where $h w_{t}, h c_{t}, h e_{t}$ are the contemporaneous values of lobster harvest at time $t$ (expressed in log form) and $h w_{t-i}, h c_{t-i}, h e_{t-i}$ are the lagged values of harvest, where $i$ represents the lags ranging from 1 to 12 . The variables $p w_{t-i,} p c_{t-i,} p e_{t-i}$ represents the lagged values of lobster prices for the west, central, and east zone respectively. Contemporaneous and lagged values of bottom level dissolved oxygen for each zone are denoted by the variables $d o b w_{t-i}, d o b c_{t-i}, d o b e_{t-i}$ and the contemporaneous and lagged values of bottom level dissolved nitrogen for each zone are given by $n b w_{t-i}, n b c_{t-i}, n b e_{t-i}$. Bottom level water temperature for each zone are represented by the variablestempb $w_{t-i}$, tempbc $_{t-i}$, tempbe $e_{t-i}$. The variables salinityb $w_{t-i}$, salinityb $c_{t-i}$, salinitybe ${ }_{t-i}$ denote the salinity level at the bottom level for each fishing zone. The variable diesel $l_{t}$ denotes the price of diesel per gallon. The variable hypoxia_dummy $y_{t}$ is a dummy variable that indicates the presence of hypoxic water conditions in western LIS in any given month. It takes the value of 1 for any month when the value of dissolved oxygen 
is below $4 \mathrm{mg} / \mathrm{l}$ and 0 otherwise. The variable dieoff _dummy $y_{t}$ is a dummy variable we include to control for the major lobster die-off that took place in the summer and fall of 1999 in western LIS (Balcom and Howell, CT Sea Grant Report, 2006).

All variables were found to be stationary except the diesel price variable, which is included in the model in first difference form. We first estimated the model with the complete set of lags to obtain the Ordinary Least Squares (OLS) estimates. For dissolved oxygen and nitrogen variables, we included a lag variable for each of the twelve months prior. For the temperature, salinity, and price variables, we started with six month lags for each variable. Based on the OLS results, we dropped the lags that were insignificant and tested the model to identify any presence of heteroscedasticity and serial correlation in the error terms. The result from the Breusch-Pagan test showed the presence of heteroscedasticity in the model while the results of the Breusch Godfrey test indicate the presence of serial correlation. We chose the Breusch Godfrey test over the classical Durbin Watson test for serial correlation because the Durbin Watson test allows us to test the presence of only first order autocorrelation. In contrast, the Breusch Godfrey test is more general and allows researchers to test the correlation between the error term at time $t$ and $t-k$ where $k$ is the number of lags chosen by the researcher. We chose $k$ equal to 12 . The presence of serial correlation makes the OLS estimates inefficient. Hence, we use the Newey-West standard errors, which accounts for the error term to be heteroskedastic and serially correlated. The results are presented in tables 1,2 , and 3 in the appendix. Table 4 provides the summary statistics for the harvest and environmental variables from the three zones.

\section{Discussion}

Past harvest levels are found to affect current harvest level indicating there is some persistence in the harvest data. In fact, for both hypoxic and non-hypoxic water zones, there is a statistically significant effect of twelve month harvest level on current landings amount. This possibly captures some of the 
seasonal effect on harvest. However, no systematic pattern emerges that explicitly shows a general relationship between past and current period harvest levels for all three fishing zones. For all three zones, the coefficients for the contemporaneous effect of dissolved oxygen are found to be statistically insignificant. The same is true for the hypoxia dummy variable. This is expected because it is likely that hypoxic conditions may not have an immediate effect on catch levels. For the lagged effects of dissolved oxygen on lobster landings, we obtained statistically significant coefficients for one month and fourth month lag for the west zone, twelfth month lag for the central zone, and third month lag for the east. These results indicate the presence of lagged effects of oxygen on lobster harvest for all three zones but the lagged effects differ for all three zones, which poses difficulty for drawing conclusion on the exact nature of these effects across fishing zones. In fact, for the west zone, we find a positive three month lagged effect and a negative four month lagged effect. This suggests that these effects may be confounded with some unobserved heterogeneity among zones or time that the model fails to capture. Surprisingly, the coefficients for the temperature variable turn out to be statistically insignificant for all three fishing zones.

\section{Conclusion}

In this paper, we estimated the contemporaneous and lagged effects of a range of environmental and economic variables on lobster harvest by Connecticut fishermen in the three contiguous fishing zones of the Long Island Sound fishery. We focus particularly on two key variables - dissolved oxygen and nitrogen - that are known influence the formation of hypoxic water zones in any waterbody. We selected Long Island Sound for our study because only the western part of the sound experiences hypoxic water conditions every year. This allowed us analyze the effects of environmental and economic variables on lobster supply from both a zone that experiences hypoxic water condition and two zones that does not. 
Our key findings indicate that there is some presence of lagged effects of oxygen and nitrogen on lobster landings. We did not find any evidence of contemporaneous effect of nitrogen on harvest in the west and central zone but a positive contemporaneous effect was found for the east zone. Also, when comparing the effects on these variables on harvest from the hypoxic and non-hypoxic zones, there is no consistent pattern seen in these lagged effects across the zones. Our results indicate that while assessing the effect of water quality changes on fish harvest, it is important to recognize the effects of lagged variables for accurate assessment. The results would be particularly useful in the context of ecosystem based management, which recognizes the interrelatedness of environmental quality and resource management.

Our results have at least a couple of policy implications particularly for fisheries management. First, the results emphasize the urgent need for accurate and detailed longitudinal data on economic and environmental variables that affect fisheries output for all ecosystems plagued by environmental issues such as hypoxia. Usually harvest data are reported in pounds/time unit. However, to capture the complete effects of hypoxia related environmental variables, researchers need access to more detailed data on landings that would allow them to study the changes in the quantity and quality of harvest over time. For example, daily data on landings concentrations of environmental variables at various locations (instead of zone specific aggregate estimates), and other relevant variables of interest (e.g. price) would allow researchers to study the impact of oxygen and nitrogen concentration on daily harvest levels, while controlling for within season day-to-day market effects. Focusing on monthly data (which were available to us) comprises our ability to study the temporal effects especially when such effects take place within shorter time frame. For example, we were not able to capture the lagged effects that may have affected harvest within the same month. Regulatory agencies that manage fisheries are in some way best equipped to gather more detailed and make them available to researchers from different fields. Second, the results indicate that there exist some lagged effects of the hypoxia related variables on harvest. This information can be used by policymakers to forecast changes in fish stock over time and analyze any significant 
changes that affect the hypoxic and non-hypoxic fishing zones in the future. This is particularly relevant for state led initiatives undertaken by Connecticut and New York, which aim to reduce nutrient discharges in the Long Island Sound in efforts to improve water quality that affect fisheries habitat. 


\section{References:}

Balcom N, Howell P (2006) Responding to a Resource Disaster: American Lobsters in Long Island Sound 1999 - 2004. CT Sea Grant Report.

Borsuk M, Stow, C, Reckhow, K (2004) A Bayesian hierarchical model to predict benthic oxygen demand from organic matter loading in estuaries and coastal zones Ecol Modeling 143: 165-181.

Breitburg, DL (2002) Effects of hypoxia and the balance between hypoxia and enrichment on coastal fishes and fisheries. Estuaries 25:767-781.

Breitburg, DL, Hondorp, DW, Davias, LA, Diaz, RJ, (2009) Hypoxia, Nitrogen, and Fisheries: Integrating Effects across Local and Global Landscapes, Ann Rev of Mar Sciences 1:329-49.

Diaz, RJ, Solow, A (1999) Ecological and economic consequences of hypoxia. Topic 2. Gulf of Mexico hypoxia assessment. NOAA Coastal Ocean Program Decision Analysis Series. NOAA COP, Silver Springs, MD.

Eby LA, Crowder, LB, (2002) Hypoxia-based habitat compression in the Neuse River Estuary: contextdependent shifts in behavioral avoidance thresholds. Can J of Fisheries and Aquatic Sc 59: 952-965.

Huang L, Smith M (2011) Management of an annual fishery in the presence of ecological stress: The case of shrimp and hypoxia. Ecol Econ. 70: 688 - 697.

Huang L, Nichols LAB, Craig JK, Smith MD (2012) Measuring Welfare Losses from Hypoxia: the Case of North Carolina Brown Shrimp. Mar Res Econ 27: 3-24.

Miller, DC, Poucher, SL, Coiro, L (2002) Determination of lethal dissolved oxygen levels for selected marine and estuarine fishes, crustaceans, and a bivalve. Mar Bio 140: 287-296.

Peterson CH, Summerson HC, Thomson E, Lenihan HS, Grabowski J, Manning L, Micheli F, Johnson G (2000) Synthesis of linkages between benthic and fish communities as a key to protecting essential fish habitat. Bull of Mar Sci 66:759-774.

Ribaudo MO, Heimlich R, Peters M (2005) Nitrogen sources and Gulf hypoxia: potential for environmental credit trading. Ecol Econ 52: 159-168.

Smith MD, Crowder LB (2005) Valuing Ecosystem Services with Fishery Rents: A Lumped-Parameter Approach to Hypoxia in the Neuse River Estuary. FEEM Work Pap. No. 115.05. Available at SSRN: http://ssrn.com/abstract=825587

Stierhoff KL, Targett TE, Power JH (2009) Hypoxia-induced growth limitation of juvenile fishes in an estuarine nursery: assessment of small-scale temporal dynamics using RNA:DNA. Can J of Fisheries and Aquatic Sc 66: 1033-1047.

Taylor DL, Eggleston DB (2000) Effects of hypoxia on an estuarine predator-prey interaction: foraging behavior and mutual interference in the blue crab Callinectes sapidus and the infaunal clam prey Mya arenaria. Mar Ecol Progress Series 196: 221-237. 
Wu J, Tanaka K (2005) Reducing Nitrogen Runoff from the Upper Mississippi River Basin to Control Hypoxia in the Gulf of Mexico: Easements or Taxes? Mar Res Econ 20: 121-144.

Thomas, P., S. Rahman, I.A. Khan, and J.A. Kummer (2007) Widespread endocrine disruption and reproductive impairment in an estuarine fish population exposed to seasonal hypoxia. Proc. R. Soc. B 274(1626): 2693-2702.

Zimmerman, R., Nance, J., and Wiams. J. 1996. "Trends in shrimp catch in the hypoxic area of the northern Gulf of Mexico.” Galveston Laboratory, National Marine Fisheries Service. In Proceedings of the first Gulf of Mexico hypoxia management conference. EPA-55-R-97-001. Washington, DC. 


\section{Appendix:}

Table 1: Results for West Zone (with significant lag variables)

\begin{tabular}{|c|c|c|c|c|c|c|}
\hline $\operatorname{loghw}$ & Coef. & NW Std.Err. & $\mathbf{t}$ & $\mathbf{P}>|\mathbf{t}|$ & \multicolumn{2}{|c|}{$95 \%$ CI } \\
\hline L1.loghw & 0.659083 & 0.0549863 & 11.99* & 0 & 0.550549 & 0.7676182 \\
\hline L2.loghw & -0.17329 & 0.0533535 & $-3.25^{*}$ & 0.001 & -0.2786 & -0.0679746 \\
\hline L4.loghw & 0.218595 & 0.0527239 & $4.15^{*}$ & 0 & 0.114526 & 0.3226638 \\
\hline L6.loghw & -0.1038 & 0.0511107 & $-2.03^{*}$ & 0.044 & -0.20468 & -0.0029112 \\
\hline L7.loghw & 0.222432 & 0.0468279 & $4.75^{*}$ & 0 & 0.130001 & 0.3148636 \\
\hline L9.loghw & -0.14813 & 0.0374258 & $-3.96 *$ & 0 & -0.22201 & -0.07426 \\
\hline L12.loghw & 0.262261 & 0.069363 & $3.78 *$ & 0 & 0.125348 & 0.3991728 \\
\hline logpw & -0.52898 & 0.3808449 & -1.39 & 0.167 & -1.28071 & 0.2227522 \\
\hline dobw & -0.0238 & 0.0325658 & -0.73 & 0.466 & -0.08808 & 0.0404751 \\
\hline L1.dobw & 0.079245 & 0.0271477 & $2.92 *$ & 0.004 & 0.025659 & 0.1328302 \\
\hline L4.dobw & -0.10992 & 0.0319919 & $-3.44^{*}$ & 0.001 & -0.17307 & -0.0467765 \\
\hline nbw & -0.02704 & 0.2461529 & -0.11 & 0.913 & -0.51291 & 0.4588336 \\
\hline L12.nbw & 0.762338 & 0.2712086 & $2.81^{*}$ & 0.006 & 0.227012 & 1.297664 \\
\hline tempbw & 0.006903 & 0.0156968 & 0.44 & 0.661 & -0.02408 & 0.0378859 \\
\hline L4.tempbw & -0.07082 & 0.0146356 & $-4.84^{*}$ & 0 & -0.09971 & -0.0419362 \\
\hline salinitybw & 0.0101 & 0.0278918 & 0.36 & 0.718 & -0.04495 & 0.0651541 \\
\hline D1.logdiesel & -3.24968 & 1.475412 & $-2.2^{*}$ & 0.029 & -6.16193 & -0.3374379 \\
\hline hypoxiad & -0.00213 & 0.117091 & -0.02 & 0.986 & -0.23325 & 0.2289951 \\
\hline dieoffdummy & -0.1408 & 0.0701675 & $-2.01^{*}$ & 0.046 & -0.27931 & -0.0023043 \\
\hline Constant & 1.22006 & 0.9830755 & 1.24 & 0.216 & -0.72039 & 3.160506 \\
\hline
\end{tabular}

* - shows statistically significant at $5 \%$ level of significance

NW Std. Err - stands for Newey West standard errors.

D1.logdiesel shows that diesel variable is in first difference form. 
Table 2: Results for Central zone (with significant lags)

\begin{tabular}{|c|c|c|c|c|c|c|}
\hline $\operatorname{loghc}$ & Coef. & NW Std. Err & t & $\mathbf{P}>|\mathbf{t}|$ & \multicolumn{2}{|c|}{$95 \%$ CI } \\
\hline L1.loghc & 0.62098 & 0.06748 & $9.2 *$ & 0 & 0.4877957 & 0.7541651 \\
\hline L2.loghc & -0.11299 & 0.0547569 & $-2.06 *$ & 0.041 & -0.2210582 & -0.0049118 \\
\hline L4.loghc & 0.186115 & 0.0489233 & $3.8^{*}$ & 0 & 0.0895555 & 0.2826747 \\
\hline L9.loghc & -0.10046 & 0.0337825 & $-2.97 *$ & 0.003 & -0.1671381 & -0.0337854 \\
\hline L11.loghc & 0.216202 & 0.0524736 & $4.12 *$ & 0 & 0.1126357 & 0.3197691 \\
\hline L12.loghc & 0.405394 & 0.0714236 & $5.68 *$ & 0 & 0.2644259 & 0.5463623 \\
\hline $\log c$ & -2.32086 & 0.7133888 & $-3.25 *$ & 0.001 & -3.728873 & -0.9128536 \\
\hline L1. $\log p c$ & 2.156301 & 0.6306836 & $3.42 *$ & 0.001 & 0.9115264 & 3.401076 \\
\hline L4. $\log p c$ & 1.26161 & 0.5568882 & $2.27 *$ & 0.025 & 0.1624845 & 2.360735 \\
\hline dobc & -0.03808 & 0.0502976 & -0.76 & 0.45 & -0.1373519 & 0.061192 \\
\hline L12.dobc & 0.090253 & 0.0372445 & $2.42 *$ & 0.016 & 0.0167434 & 0.1637619 \\
\hline nbc & 0.305917 & 0.3103247 & 0.99 & 0.326 & -0.3065685 & 0.918402 \\
\hline tempbc & -0.01614 & 0.023433 & -0.69 & 0.492 & -0.0623884 & 0.0301108 \\
\hline salinitybc & -0.10428 & 0.0386598 & $-2.7^{*}$ & 0.008 & -0.1805776 & -0.0279725 \\
\hline L1.salinitybc & 0.130963 & 0.0442202 & $2.96 *$ & 0.003 & 0.0436862 & 0.2182404 \\
\hline L2.salinitybc & -0.21196 & 0.0415633 & $-5.1^{*}$ & 0 & -0.2939885 & -0.1299224 \\
\hline D1.logdiesel & -2.98762 & 1.103701 & $-2.71 *$ & 0.007 & -5.165988 & -0.8092584 \\
\hline Constant & 3.244201 & 1.509367 & $2.15^{*}$ & 0.033 & 0.2651766 & 6.223225 \\
\hline
\end{tabular}

\footnotetext{
** - statistically significant at $10 \%$ level of significance
} 
Table 3: Results for East zone (with significant lags)

\begin{tabular}{|l|r|r|r|r|r|r|}
\hline \multicolumn{1}{|c|}{ loghe } & Coef. & NW Std.Err. & \multicolumn{1}{|c|}{$\mathbf{t}$} & $\mathbf{P}>|\mathbf{t}|$ & \multicolumn{2}{|c|}{$95 \%$ CI } \\
\hline L1.loghe & 0.6516362 & 0.0802238 & $8.12^{*}$ & 0 & 0.49333 & 0.8099423 \\
\hline L2.loghe & 0.3010111 & 0.0467057 & $-6.44^{*}$ & 0 & -0.39318 & -0.2088464 \\
\hline L4.loghe & 0.1367275 & 0.0381361 & $3.59^{*}$ & 0 & 0.061473 & 0.2119817 \\
\hline L11.loghe & 0.2167053 & 0.0544112 & $3.98^{*}$ & 0 & 0.109335 & 0.3240753 \\
\hline L12.loghe & 0.3329142 & 0.0779119 & $4.27 *$ & 0 & 0.17917 & 0.4866582 \\
\hline logpe & 0.2824286 & 0.2480358 & -1.14 & 0.256 & -0.77188 & 0.2070218 \\
\hline dobe & 0.0181023 & 0.0250895 & 0.72 & 0.472 & -0.03141 & 0.0676115 \\
\hline L3.dobe & 0.0364283 & 0.012585 & $2.89^{*}$ & 0.004 & 0.011594 & 0.0612624 \\
\hline nbe & 0.4149124 & 0.2115694 & $1.96 *$ & 0.051 & -0.00258 & 0.8324035 \\
\hline tempbe & 0.0027412 & 0.0054299 & 0.5 & 0.614 & -0.00797 & 0.0134561 \\
\hline salinitybe & 0.0247222 & 0.0247184 & 1 & 0.319 & -0.02405 & 0.0734991 \\
\hline & & & & & & \\
\hline D1.logdiesel & -1.154156 & 0.5373975 & $-2.15 *$ & 0.033 & -2.21461 & -0.0937062 \\
\hline Constant & -1.353949 & 0.9782223 & -1.38 & 0.168 & -3.28428 & 0.5763826 \\
\hline
\end{tabular}


Table 4: Summary Statistics for harvest and environmental variables from three fishing zones for $1995-2011$

\begin{tabular}{|c|c|c|c|c|c|}
\hline Variable & Obs & Mean & Std. Dev & Min & Max \\
\hline hw & 204 & 45114.88 & 90409.98 & 29 & 512439 \\
\hline hc & 204 & 27422.53 & 51075.46 & 10 & 295103 \\
\hline he & 204 & 34374.56 & 38359.24 & 606 & 196733 \\
\hline dobw & 204 & 8.086328 & 2.84119 & 2.284 & 13.196 \\
\hline dobc & 204 & 8.534485 & 2.167238 & 4.561 & 12.971 \\
\hline dobe & 204 & 8.841968 & 1.460478 & 6.4 & 12.637 \\
\hline nbw & 204 & 0.343353 & 0.0848899 & 0.178 & 0.614 \\
\hline nbc & 204 & 0.27812 & 0.0763621 & 0.1 & 0.55 \\
\hline nbe & 204 & 0.228493 & 0.0590376 & 0.127 & 0.533 \\
\hline tempbw & 204 & 11.15599 & 6.895618 & -0.815 & 22.488 \\
\hline tempbc & 204 & 11.28666 & 6.912208 & -0.125 & 22.186 \\
\hline tempbe & 204 & 11.06335 & 6.086117 & 0.588 & 21.163 \\
\hline salinitybw & 204 & 26.95325 & 0.9321671 & 24.886 & 29.104 \\
\hline salinitybc & 204 & 27.92949 & 0.841995 & 25.822 & 29.837 \\
\hline salinitybe & 204 & 30.25755 & 0.7345759 & 28.356 & 32.107 \\
\hline
\end{tabular}

